\title{
Thinking of Video Essays as A Performative Research With A New Concept: Transimage
}

\author{
Süleyman Kıvanç Türkgeldi*
}

\begin{abstract}
As the daily use of videographic tools increases, searches and trends for new forms of expression emerge. It has even become possible to say that this situation can affect the ways of thinking. At this point, it has become necessary to define an academic status to the video-essay genre, which is shown as a new way of expression and experience, in the context of film studies. Although video-essays, which can be a part of the search for a performative method, remain at an ambiguous point, we can state that videographic approaches have become widespread in the field of film studies. From this point to forth, this study proposes to consider the concept of transimage in order to use video-essays in film studies. Discussing the concept of transimage can be a new path to think on the images of the film with other images.
\end{abstract}

Keywords: Video-essay, Transimage, Performative method

ORCID ID : https:/ / orcid.org/ 0000-0002-6465-923X

E-mail : kturkgeldi@gmail.com

DOI: 10.31122 / sinefilozofi.823234

Geliş Tarihi - Recieved: 08.11.2020

Kabul Tarihi - Accepted: 30.04.2021 
- Makaleler -

\title{
Performatif Bir Araştırma Olarak Video Denemeleri Yeni Bir Kavram ile Düşünmek: Transimaj
}

\author{
Süleyman Kıvanç Türkgeldi*
}

$\ddot{O} z e t$

Videografik araçlar gündelik pratiklerin içerisine dahil oldukça ifadenin yeni formarma yönelik arayışlar ve eğilimler yayginlaşmaktadır. Hatta bu durumun düşünme pratiklerinin kendisine de etki edebileceğini söylemek mümkün hale gelmiştir. Tam da bu noktada sinema üzerine düşünmenin ve düşünceyi ifade etmenin yeni bir yolu olarak gösterilen video-deneme türüne film çalışmalarn bağlamında akademik bir statü kazandırmak gerekli hale gelmiştir. Performatif bir yöntem arayışını parçası olabilecek video-denemeler her ne kadar muğlak bir noktada dursa da film çalışmalarn alanında videografik yaklaşımlar yayginlaşmaktadır. Bu çalışma, bu sorulardan hareketle video-denemeleri film çalışmalarında kullanabilmek amacıyla transimaj kavramını düşünmeyi önermektedir. Transimaj kavramın tartışmak filmin imajlarını üzerine yine imajlar ile düşünmenin bir yolu ve kalkış noktası olabilir.

Anahtar kelimeler: Video-deneme, Transimaj, Performatif yöntem

ORCID ID : https:/ / orcid.org/ 0000-0002-6465-923X

E-mail : kturkgeldi@gmail.com

DOI: 10.31122 /sinefilozofi.823234

Geliş Tarihi - Recieved: 08.11.2020

Kabul Tarihi - Accepted: 30.04.2021 


\section{Introduction}

There are two people sitting in a living room and are watching a movie. Now let us imagine that one of them is blind. How does the non-blind person tell the blind one what they are seeing? The blind person hears what is happening and is in a receptive state towards the cinematic output. But he or she cannot witness the actions of the actors, the colours, the mimics, the scenery, the movement of the camera, the cut, the Mise-en-scène...How does the person who is witnessing all of these information's all at once, translate this grand total of cinematographic information?

A truly short answer to this question is 'Not in its totality'. But then a second question arises about the explanatory nature of cinematography. If the blind person would be perfectly capable of seeing but the narrator would not be aware of this fact and continue with the describing of the moving images, would the playing blind person be inclined to witness the cinematographic interpretation as the 'film', the interpretation of the film, or as both?

These are of course only thought experiments that have wide and vastly different answers but herein the fundamental question of this essay; Can a videographic approach be postulated towards an academic structure that recognizes its need in the scientific space?

After this tough question, we can begin to discuss our issue by drawing attention to the point emphasized by Polanyi. Michael Polanyi (2009, p. 4), while saying, "we can know more than we can tell," pointed to the gap between knowing and linguistic expression. "Take an example: We know a person's face, and can recognize it among a thousand, indeed among a million. Yet we usually cannot tell how we recognize a face we know. So, most of this knowledge cannot be put into words" (2009, p. 4). Recognizing a face is the result of a talent that we have always possessed. When we recognize a face, we cannot express nor explain how we do it. Nevertheless, we still recognize. Polanyi takes a stand against the established understanding that there is only one way to know and express it. Eisner (2008, p. 5) states that although we have very few words to describe the taste of water and how music sounds, yet we know them. Words become agents of direct experience, except when used artistically. Words direct us in a direction that we think they reveal. Therefore, words are like clues to guide us in the signification journey. However, the benefit of these clues depends on their ability to help us (Eisner, 2008, p. 5). The common point of Eisner and Polanyi is that they stated to the differences between consciousness and the potential of language to comprehend life. Wittgenstein argued that language is already the limit of thought, so language is already what determines consciousness. However, we should point out that what is expressed here by the word emptiness is not such a "mystic" substance in the Wittgensteinian sense. In this study, the gap is more related to the loss of meaning arising from the conceptualization / effort of conceptualization, of aesthetics. For example, poetry is the transmission of emotions that cannot be expressed in language through words. Because its metaphorical power can take it from a linguistic dimension to an imaginary dimension. However, the expression of scientific knowledge is pure and precise. Therefore, the boundaries of the language that serve to express scientific knowledge are rigid and clear. This context should be understood when talking about the limits of language in this study.

Langer (1957, pp. 21-5) expresses this by dividing information into two different types. The language we use every day, communicate, create concepts, and form theories, is a discursive language. Therefore, the information we can express through discursive language is the discursive form of knowledge. According to Langer there is also a non-discursive information form, that discursive language cannot grasp and express. Although it is not difficult to express the situations and experiences that we know, there are times where we cannot find a word to express new experiences and situations. Or, although concepts that correspond to the most prominent (anger, happiness, sadness, fear, etc.) states of our emotional world exist in the language, no word corresponds to hundreds of different emotional states in between (Langer, 1957, p. 22). 
In exactly this state, purely as a device, the expressive limitation of writing makes it difficult to discuss the cinematographic aspects of film. Throughout the history of film criticism and film studies, discussing the organization of the in-frame elements of a film, trying to describe the movement, talking about the rhythm of the montage, discussing the aesthetic effects of light, reflecting on the sounds of the film, or questioning the relationship between different images, has generally been expressed textually.

So, it is possible to say that textual expression is the traditional method in this endeavour. However, today's technological tools make possible alternative methods of expression that can go beyond the traditional method. Naturally, we can say that one of the apparent reasons for the discursive trend in the field of film studies is the traditional formats of academic platforms. However, cinematographic images can only be expressed in a limited way within the mediating structure of language. In a broad sense, the cinema; which exists outside the boundaries of discursive language and is in a state of continuous formation changes much faster than the concepts of language, -if we think from a Deleuzian perspective- it expresses itself with movement and time blocks.

For this reason, studies on film aesthetics are sometimes faced with a methodical problem. Some studies, while examining film, try to describe and discuss images that are difficult to express verbally through a discursive language. At this point, it is necessary to reflect on the confusion. To understand the reason of this, we may have to question whether methods that are quite useful for other fields of social sciences are always equally suitable for film studies, rather than just finding these studies methodically inadequate.

When we start thinking about a movie, how much of the scientific methods that we learned during academic education can be functional tools for interpretation? First, we cannot deny the subjective dimension of thinking about a movie. We should also reconcile with the idea that thinking on cinematic images does not have to be scientific. At this point it is worth making a small note: Post-1970's theory, at least in Anglo-Saxon doctrine, entailed a steadfast rejection of the descriptive (always bilateral, subjective, rhetorical, misleadingly mimetic) to return to more scientific or technical language (Stern and Kouvaras 1999, p.12 cited. Shambu 2020, p. 20). This statement may be a clue to the origin of today's confusion, especially when we take into account the presence of the Deleuze effect, which has increased its intensity especially in the field of film studies after the 90's. Deleuze insistently stated the concepts in hand (in psychoanalysis or linguistics) are not $t$ usable for cinema. Because the images of cinema and its ungraspable nature are always mutating. We need to think cinema like microbiology or brain $(2013,68)$. Maybe this was the best analogy for Deleuze.

At this point, a discussion based on a similar reflex can make a positive contribution to the aforementioned confusion. For this very reason, the aim of this study is to investigate the possibility of using video essays as a method of performative thinking and expressing it with the concept of transimage. But before we can start to discuss this endeavour however we need to ask some questions in the first place: The fundamental question is of course; How can we extend the practice of thinking and expressing visual and auditory images in film studies? In fact, -especially in descriptive film writings- this question is important as it points to the gap between the impression of an image and the expression of that impression. As digital platforms evolve and become rich in audio-visual content, it has become possible to come across many video-essays about cinema. In the entire corpus, it is possible to mention a wide variety of different video-essays. Due to this rapid change and diversity in today's media, it is not currently possible to find a clear answer to this question. However, it must be admitted that this issue has a potential power that will emerge as time progresses and more discussions are held. Therefore, in order to answer this fundamental question, two sub-questions must be answered first. The first sub-question is for what purposes video essays can be produced. The second sub-question is how it can be produced for these purposes. These two sub-questions 
are important in order to be able to think of video-essays as a performative method, to clarify the areas of consensus, albeit not rigid. Thus, to discuss a different approach, we can question whether video-essays can be both a support and alternative method to film studies. For this inquiry, a key concept is needed in this study. This concept is transimage.

Firstly, the mutual gap between the images of the film and the depiction of those images will be considered. Then, the devices that change with technology and the effect of these devices on expression will be briefly discussed at a historical level. Next, video-essays and concept of performative research will be discussed in the context of the expression of a transimagery way of thinking. Finally, to make a classification in this field for future reference, the purposes with which video essays can be used and in what forms they can appear in line with these purposes will be discussed. In the conclusion part, some suggestions will be given to elaborate these discussions further.

\section{The Gap Between Image and Its Description}

Like all visual arts, cinema can transcend language. Because the plane of cinema is the plane of images. However, when we start talking about images, we take these images from the plain where they belong to and bring them into the plain of words. In the plain of words, we try to explain images with concepts, and we sense that these concepts are often inadequate. Because we cannot find concepts that correspond to every moment of cinema, just like the absence of an expression that corresponds to every emotional state. At this point, we sometimes make use of the terminology of filmmaking. However, we should point out that this terminology is a group of concepts that can only partially describe what we are experiencing.

Honestly, it is quite difficult to describe a movie in text, trying to think about its dimension that cannot be described with text in a textual way. Discussing on camera movements, the sound, the rhythm of the editing, the changing colours, the light, the composition, in short, the unique way of cinematic thinking with language will inevitably lead to the loss of the meaning and feeling of the images considered. Cinema has always thought in its own way from the very beginning. Therefore, we must say that the textual reduction we are talking about is not arbitrary, but ontologically inevitable. Descriptive writings on cinema are certainly not worthless in this context. However, sometimes they resemble translation processes. The reader reconnects with the film through some descriptions. The writer's interpretations of the images left from the film in his memory with the images of the film in the reader's memory. The author's interpretations of the images of the film come across with the images that remain in the reader's memory. This dialectical process arises between what is said about the film and what is received about the film. However, we can still say that in this dialectic the desired point cannot always be reached exactly, or that there may be more of a different plane of compromise.

The answers that Frampton sought to the question of "how should a film script be" is essentially an effort to find a way to minimize the gap between word and image. Frampton puts it this way: "From an image we can only capture what is caught in the web of our language; We look at images with words" (2013, p. 263). Hence Frampton highlights the necessity for a transformation of language in film studies (at least in the context of aesthetic interpretation of films). While talking about filmosophical interpretation, he also discusses transformations towards a writing style: When dealing with a film, he demands more poetic style instead of empirical expressions (2013, p.276). There is a common desire between what Frampton points out and the answers to the question of why we need video-essays in film studies. Aside from Frampton's idea of poetic style, today's image production tools can provide us some alternative ways. 


\section{Expression and Its Medium}

Eisner $(2008$, p. 5) stated that, technology offers new tools for each generation to increase and diversify representational possibilities. This makes new forms possible. McLuhan (2001, p. 38) emphasizes that, when a new technology is included in super culture and if that technology focuses or gives superiority to one or the other of our senses the ratio between all our senses will change. Different communication technologies develop, expand and change the communicative characteristics of humans. Communication tools, which come to the fore in different periods, affect the definition of the characteristic features of human communication skills (Rowland, 2014, p.10). Havelock (2014, p.94) stated that the process of preserving knowledge in pre-literacy culture is possible through verbal structures that can be sung with music, expressed through rituals and can be called verbal texts of the time. Since the word is conveyed in the form of music, information is expressed in an acoustic structure. The invention of writing, on the other hand, freed verbal expression from the limits of acoustics. Any information could be recorded without worrying about rhythm, and mental energy spent for memorizing was started to be saved (Havelock, 2014, p. 94). In addition, the transformation of verbal content into writing has led to a physical form that can be considered and changed (Logan, 2014, p.100). Thus, some unpredictable innovations emerged with the alphabet. Because the alphabet made it possible to use and transfer unknown and unexpected expressions, to stay fixed in one place, to be read and re-read, thus increasing its influence and spreading among people and generations (Havelock, 2014, p.94). So, the invention of writing is a technological invention and a new possibility of expression. The point to be underlined is that; the media in which the content is organized and created determines the style of the arrangement (Logan, 2014, p.100). Cinematograph, which is a part of visual culture today, was a technological invention first and then has become a new possibility of expression. However, thinking about a film in a literary form has been the most practical method that can be applied for a long time. Due to the technological conditions, thinking cinematographic and thinking about cinematography could be performed by different means. Over the last century, it can be said that writing is technically easier to produce, share and distribute, and its possibilities are wider in this context. And this has made it more possible to produce literary expression in the field of film studies. New technological tools, on the other hand, take our relationship with movies to a different dimension. Perhaps the most important aspect that has changed since the times when films were only watched in the movie theatre is that they can now be accessed at any time. In addition, the ability of digital technology to play movies back and forth as they wish, regardless of a specific time and place, and the ability to divide them into pieces has opened the way for different potential perceptions. This change of the tools we use while looking at the films also allows us to ask new questions about cinema.

So, we can go back to the point highlighted at the beginning of this chapter and say the following: Since video-essays have the power to use cinematographic possibilities, like montage, colours, sound, in short, images, they open the way for different thoughts and ways of thinking, creative comparisons, compositional forms and even interpretations. In this respect, while discussing the cinema using its medium and composing the thought through this medium can create new ways not only in form but also in content. Cinema gives an audiovisual form to a narrative with its movement and time blocks. That is exactly what the ontology of cinema is. Therefore, to think about cinema with the medium of cinema brings the way of thinking about cinema to a different level.

Assembling and remixing images from different films is undoubtedly a creative action. In doing so however, it creates a field of experience by using the technical possibilities of editing and rediscovering the limits of the narrative in the video's own medium." (Gürkan, 2019, p.287). Just as the transfer of the word to the writing brought new possibilities to the expression, the possibility of expressing the image with its own tools will save it from the limitations of the text, fill the gaps left from the text and support it, and create creative and alternative ways. 
Because writing is just one of the means of expression. Thinking about cinema may inherently demand other means of expression. Based on what has been explained so far, it is worth recalling once again the discursive and non-discursive form distinction Langer made regarding the expression of knowledge. It is possible to see that the widespread use of video to this extent in the last two decades has created significant changes. According to Groys: "Today, people are more interested in producing images than consuming images" (Groys, 2010, cited in Shambu 2020, p32). Thus, we can say that video, which changes, distorts and re-establishes the structure of traditional media and which can almost penetrate the practice of life with the internet, has become a common means of expression. If the cinematographic devices have included moving images in our lives, then we can say that the hallmark of video is the democratization of these images. And one of the benefits of this democratization process is that cinematographic images can be parsed and combined again in a video file format by anyone.

\section{A Transimagery Thinking Form with Video-Essay}

Baker (2015, p.59) emphasized that video should not be just a piece of device or a cinematographic tool. Video is a breaking point in the context of the democratization of images. It can be said that the invention of video has more benefits than facilitating documentary and film production to a certain extent. Because a video can be about anything, it is not just limited to producing a movie or documentary. It is possible to say that technical, explanatory or poetic studies about movies have started to increase. The experience of watching movies, which has no limitations in terms of time and space today, brings to mind the following statement of Baker: "Sharing, democratizing, and cross-reading the images again and again..." (2015, p.59). Video-essays can be considered just in this range. The creation of new semantic levels and new images from film images with manipulative montage techniques. In fact, this brings us back to Eisenstein's montage theory. Eisenstein was describing the power of the montage in the movie, but what he thinks is not different from what is meant here. To establish a connection between images that do not have a time-spatial relationship with each other, by using different images that is, to create a new context or, more generally, to make a new interpretation. This idea is not far from what Eisenstein said about the nature of montage. At this point, a new meaning / interpretation can arise from the interaction of a film with another film, with text or sound, it is causally related to the nature of the video-essays.

Keathley (2011, p. 178) emphasizes that DVD technology and the internet are important breaking points for many film critics outside of academia to contribute to the field of cinema through blogs. However, these breaking points are not limited to the invention of DVD and internet:

"If we want to examine the changes to film criticism brought about by DVD availability, we must consider more fully the intersection of cinema, DVDs and other digital technologies - not just the internet, but also a variety of accessible and affordable software programs that enable sophisticated image and sound manipulation, such as iMovie and Final Cut Express. For beyond simply having access to movies on DVD, the full range of digital video Technologies enables film scholars to write using the very materials that constitute their object of study: moving images and sounds. To paraphrase Jean-Luc Godard, film scholars can now answer images not only with words, but also with other images (Keathley, 2011, p.179) ".

It is a creative destruction process that an image can be separated from its context and be used for another context and can be separated from its whole in order to express an idea. Mcwhirter (2015, p. 369) defines video-essays essentially as movies or short films about film culture. However, in the last decade, the same term has also become a term that defines the video-criticism type of productions produced about the cinema arts and rarely television (2015, p.369). It can be said that these short videos are called essays because there is no consensus on their form and more importantantly they emerge from an experimental approach. These 
compositions "can discover or recreate a narrative or context that the director perhaps did not deliberately show, or perhaps not yet discovered by herself/himself. The audio-visual essay allows all of these and opens up a space of creativity and freedom for both the cinephile audience and the person making the video essay" (Gürkan, 2019, p.294). The reorganization of audio-visual material is essentially a new form of expression. Most importantly, it has the power to fill the gaps that language has. Gürkan (2019, p. 301) states that video graphic film criticism contributes to the emergence of meanings that words have difficulty (to) expressing in text-based criticism, and that this meaning is revealed through direct "showing", not through representation or metaphors. Shambu expresses his thoughts on this subject as follows (2020: 22)

"In fact, the most interesting of the online demonstration reviews about cinema today are in non-traditional, innovative forms such as video essays and cinematic Tumblr accounts. Studies in this form often avoid film descriptions in the critically illuminating traditional script; instead, they resort to image citations, references, intertextual relationships and fruitful overlaps that allow critical understanding. In other words, while written descriptions have the power to vividly evoke memories of long-watched films, critical practice based on demonstration follows a different logic."

In this sense "audio-visual essays involve a certain resistance and criticism. It offers an alternative narrative to traditional text-based academic studies. Moreover, this narrative makes the experience of the audience and even its producer unique and subjective." (Gürkan, 2019, p.301). In this respect, the possibilities of the video provide a critical advantage to this form of expression that arises from itself. Contrary to the previously quoted statement Frampton's "we look at images with words" now we say, we could look those images with other images. According to Gürkan (2019, p. 299), being able to intervene in the linear flow of the film with images may allow the emergence of connections that have not been thought of before, for example, to discover certain common patterns that repeat. In the textual dimension, intertextual analysis is one of the frequently used qualitative methods in film studies. However, the concept of intertextuality tends to reduce cinema to a text. However, with the possibilities provided by video-essays, a different type of connection can be mentioned. This is a type of connection that can be called interimagery at first glance, or even conceptualize it for film studies in this way. However, at this point, we may need a concept beyond the concept of inter-image. Different images come together in a video-essay and have the potential to form another new image. There is a need for a concept that transcends the images of the two films by combining them and include the possibility of a new meaning. Here, imagery links do not have to be only between two films. A link can also be established between a film and the images recorded by the creator of the video-essay, between a sound recording and a movie, or a film and a painting or photograph. The images of the film can be manipulated, or they can be used in combination with various graphics and animations. Similarly, the number of links can be increased. Therefore, here we can talk about a concept to name this form of connection: "transimagery" which includes all images that transcend to themselves. But this transcendency is not to deny the existence of particular images that relate to each other. There is no restrictive barrier in this relation, and it accepts the imagery transience to create new images that (to/ for???) constructs new meanings and possibilities. Transimagery can offer not only a concept but also a perspective that can pave the way for new methods in film research. It can enable the video-essay genre to be considered beyond being a descriptive, text-oriented design that stays on the periphery of the text and illustrates the written expression. This perspective can lead us to discuss different research models which new images can be created through images. Therefore, the creative potential of the video-essays is not excluded. Transimagery forms of expression mentioned here puts practice (like editing, shooting, sound recording,etc.) at the centre. Hence these productions may need to be considered as a performative method in essence. 


\section{Video Essays as Performative Method}

In the discussions about the practical equivalence of video essays, Grant emphasizes that not only considering this as a new way of film criticism performed with its own mediums but also a new methodological opportunity in the field of film studies (Grant, 2016, p. 255). According to Grant, audio-visual essays can be considered within the boundaries of a performative research method as an alternative to quantitative and qualitative research, especially in the field of cinema and television (2016, pp. 255-6). Grant explains this method of performative research at this point with reference to Haseman's "A Manifesto for Performative Research". In the first paragraph of this work Haseman highlights their standpoint as follows:

"We stand at a pivotal moment in the development of research. Established qualitative and quantitative research methodologies frame what is legitimate and acceptable. However, these approved approaches fail to meet the needs of an increasing number of practice-led researchers, especially in the arts, media and design. Within the binary of quantitative and qualitative research, these practice-led researchers have struggled to formulate methodologies sympathetic to their fundamental beliefs about the nature and value of research (Haseman, 2006, p. 98).

In this inquiry Haseman underlines a paradigm for the performance / practice to be the research itself rather than a tool of research: "There has been a radical push to not only place practice within the "research process but to lead research through practice. (2006, p.100)". This standpoint is definitely a demand for alternative expressions in research methodologies. Since art and artistic experience are inherently incommensurable and the expression of artistic experience is distorted at the semantic level during linguistic transfer.

Haseman highlighted several characteristics of basic performance-based work. In the most general sense, the core of this kind of work is experience (2006, p.100). It should also naturally have a research question in quantitative and qualitative methods. The purpose of the research is to prove or reject a hypothesis by discussing this question. At the departure point of a performance-based study, there is no question in the sense required by quantitative and qualitative methods. Although it is a fundamental issue of the research, the point where it will go in general is uncertain. Or it is not tied to the methodological limits of quantitative and qualitative research (2006, p.100). Haseman underlines that the research outputs of performative methods should be considered on a symbolic level of expression. Therefore, it can be said that a performative study is an effort towards the experience itself rather than about the transformation of some findings into measurable numbers (quantitative) or words (qualitative) (2006, p.101). At this point, we can say that the most basic principle that distinguishes the performative approach from other traditional approaches is the expression of the findings. Hence in a performative study, symbolic forms that are different from numbers, words and discursive language are used to express the findings (Haseman, 2006, p.102).

According to Langer, performative forms do not depend on the linear and sequential structures of discursive and arithmetic writing. On the contrary, these forms are more functional as they are integrated and simultaneous with the presentation they are in (Langer, 1957: 97 cited in Haseman, 2006, p. 102). Therefore, when research findings are desired to be expressed in a performative form, material forms of symbolic language such as still image, moving image, forms of music and sound, live performance or digital code are used. For example, Saldana, describes the ethno theatrical work made with performative methods as follows:

"Ethnotheatre employs the traditional craft and artistic techniques of theatre production to mount for an audience a live performance event of research participants' experiences and/ or the researcher's interpretations of data. This research-meaning, to investigate, in its broadest sense-can be conducted by artists, scholars, or even by the participants themselves in such 
diverse fields of study as sociology, anthropology, psychology, education, health care, women studies, justice studies, ethnic studies, cultural studies, political science, journalism, human communication, performance studies, and theatre. The goal is to investigate a particular facet of the human condition for purposes of adapting those observations and insights into a performance medium Simply put, this is preparatory fieldwork for theatrical production work. An ethnodrama, the written script, consists of dramatized, significant selections of narrative collected through interviews, participant observation field notes, journal entries, and/or print and media artifacts such as diaries, television broadcasts, newspaper articles, and court proceedings. Simply put, this is dramatizing the data" (2005, p. 1).

According to Haseman (2006, p. 102), the most fundamental difference of performative method from qualitative and quantitative research methods is the way of expressing the findings. These forms of expression belong to a plane that cannot be expressed with numerical data but transmitted through symbolic data (moving / still image, sound and music forms, etc.) outside the boundaries of language. Haseman uses the following table to clarify where these three methods differ from each other:

\begin{tabular}{|c|c|c|}
\hline Quantitative research & Qualitative research & Performative research \\
\hline $\begin{array}{l}\text { "the activity or operation of } \\
\text { expressing something as a } \\
\text { quantity or amount - for example, } \\
\text { in numbers, graphs or formulas } \\
\text { (Schwandt, 2001: 215) }\end{array}$ & $\begin{array}{l}\text { Refers to "all form of social } \\
\text { inquiry that rely primarily } \\
\text { on qualitative data ... i.e. } \\
\text { nonnumeric data in the form of } \\
\text { words } \\
\text { (Schwandt, 2001: 213). }\end{array}$ & $\begin{array}{l}\text { Expressed in non-numeric data, } \\
\text { but in forms of symbolic data } \\
\text { other than words in the discursive } \\
\text { text. These include material forms } \\
\text { of practice, of still and moving } \\
\text { images, of music and sound, of live } \\
\text { action and digital code }\end{array}$ \\
\hline The scientific method & Multi-method & Multi-method led by practice \\
\hline
\end{tabular}

Table 1: Key differences between the three research paradigms (Haseman, 2006, s. 103).

Haseman (2006, p. 103) underlines the word "practice", which he stated in the table for the performative method. The practice led statement here indicates that practice is not an option, but a necessity of the research. At this point, it can be said that Haseman sees the performative research method as an alternative and innovative approach to grasp research issues that cannot be probed sufficiently due to the limitations of other methods. According to Haseman (2006, p.104-5), a researcher who uses performative method should develop her own methods to examine practical facts in order to obtain a new perspective, a new interpretation and representation on the subject being studied.

Here we can refer to an effort to seek a different expression of the non-discursive knowledge that Susan Langer spoke about. Dougless and Carless (2013, p.54) emphasize that the performative research method is a different way to reach information with this justification. This path also allows for an experiential process.

"At different times, we have found that the understanding or knowledge we 'discover' through these processes enlarges, deepens, enriches, complexifies, or challenges knowledge generated through traditional modes of analysis. In short, we have come to realise that performative methods have the potential to result in unique insights into human experience and social issues" (2013, p.55)

In a very general context, we should say that expression and experience are important in a performative approach. Dougless and Carless (2013, pp.55-6), also, argue that performative research as an overarching form of representation is a form that can include those who are interested in the field or those outside the academy. In a sense, they even emphasize that academic studies are within the boundaries of the field in the context of contacting others. 
Although terminological language and expressions can be called natural in every field of science, if we think through a very concrete example, we know that cinematographic means of expression - which evolve due to a constantly changing and developing technique - cannot be a consensus on the linguistic counterpart. This can turn into a communicative problem in the field of film study. Grant (2016, p. 256) emphasizes that video-essays are both an effective and affective way, especially for film studies, and that we need new and alternative experiments in a methodological context. While underlining that there is still a long distance to be covered in order for the idea of such a method to be an acceptable and useful method, it also emphasizes that this path can only be enlightened with more trials and discoveries (2016, p.256).

Performative methods can, of course, be a supportive element of qualitative research. However, when a separate paradigm is mentioned, it is necessary to go beyond this limit. In this context, the performative expression becomes central to the research. When we think about cinema, we can say that performative methods are a different way of an inquiry, a different layer of the relationship established with films and a different expression of this. We can say that thinking about the movement and time images of cinema, again with the movement and time images of our interpretation, deserves to be considered as a performative method. However, the fact that video testing can be used on its own will require a complex and challenging discussion. The first meaning evoked by the concept of method is a roadmap with clear boundaries used to concretely verify a certain point of view in research and to reach a finding. First, it should be underlined that the approach mentioned here is different from the positivist paradigm. Transimagery connections cannot be thought of like the laws of physics. These connections are subject to the qualitative limits of philosophical / artistic interpretation, not to the judgment of precise scientific principles. When considering cinema, it can be said that there is a need for such an approach. The amorphous nature of visual culture, digital interaction and the new cultural changes that arise from it, the production tools of cinema that allow new technological possibilities show that the kinds of expression, namely their images, change and evolve very rapidly due to these changes. Therefore, it is possible to say that especially the evolving speed of language has difficulties in capturing and conceptualizing the change in the image. This is, also, not just about the two different expressions which progressing asynchronously. As mentioned at the beginning of the study, there is already a gap between written expression and visual expression that is difficult to pass. For this reason, the need for transimagery ways of thinking and performative methods that can express these forms should be considered as a topic worth discussing.

\section{Types of Video-Essays in Film Studies}

The variety of video essays broadens the definition of the term, and this variation may cause some differences in context. Also, limiting the types of video-essays does not seem to be useful in practice. Different video-essays produced every day may demand different categories. It may not even be categorized. However, in order to facilitate a basic discussion, some different forms can be mentioned depending on the usage areas of video-essays. For example, Damon Smith (2011) makes one of the distinctions on this subject as "Standard Video Criticism" and "Non-Standard Video Criticism". The first refers to a production created with an authoritative sound style superimposed on the footage of the film, the second to a production style that uses cinematic tools and can go beyond the meaning of the film.

Here we can say that the main point of the distinction between two different tendences are textuality and imagery. When Smith combines video criticism with the explanatory style of an authoritative voice and calls it standard, he actually describes the common explanatory form of a textual / verbal genre. We can say that he thinks the Non-Standard Video Criticism conceptualization at more imagery level than this textual one. Keathley (2011, p.180) emphasizes that video-essays could be in the form of expression that does not remain within the boundaries of language, transcends it, and can take place at more imagery and poetic level as well as analytical and linguistic-centred. Accordingly, it makes a triangular distinction in 
very general terms (2011, p.180). We can say that video essays in the descriptive audio format added to the images obtained from the film are the most common form. It is a product of a language-centred approach. Another is that it combines the footage of the films and the essayist's thoughts about the film (in voice-over or subtitle format) by modulating them in sync. At an even more extreme point, we can mention a form created by completely manipulating the visual and auditory images of the film and using other visual and audio materials and effects. If we consider the explanatory and poetic video essays here as two separate poles, it is possible to say that there might be many different forms of expression between these two poles (Lopez \& Martin, 2015, p.81). We should underline that the form that Keathley defines as analytical and language-centred is especially important educationally. For example, this method should already be a part of education in order to analyse the cinematographic language of a film in depth. This form can also be used for academic studies, such as relating a concept with a movie, to better understand the subject in practice, i.e. to illustrate it in a sense.

The second one is a form created by combining the film and sections taken from other images outside the film to give a understanding to the general context of the films nature. The emphasis here is on the transformation of criticism into a new form of audio-visual, more effective and even appealing to the audience's emotion. This type is: "rather than simply lowering the audio track and having the critic's voice in its place, the essayist can carefully modulate both image and soundtrack to coordinate with his remarks Keathley (2011, p.180).

Third, we can say that it is a poetic form that can stand at the intersection line of academia and art, and sometimes even has the freedom to overflow the edges of this line. According to Keathley (2011, p. 180), the emergence of the possibilities of multi-media presentations on the internet demands that the analysis on the film be expressed with more impressive and poetic discourse. So, it can modulate different creative possibilities in an unlimited way. It should be noted that the line between these different forms does not have to be very sharp. As Mcwhirter has stated, since it is still in the development phase, a complete line has not been determined on how the form of video-essays should be $(2015$, p.377). The fact that this line is too definite can turn into an obstacle that will limit the creative multiplicity of video-essays. So perhaps it will be necessary to consider the concept more modular. So, we may need a perspective that covers many definitions rather than a complete definition.

As can be seen, many different opinions are put forward on the general form of video essays. What determines the meaning of a tool is its use. Video-essays can also make sense according to the area in which they can be used. According to the meaning they have gained, it seems more possible to make more specific classifications on the forms of video-essays. Indeed, the area to be used is also the context. Now, a general classification can be thought over various contexts. In later studies, more detailed discussions can be made on the formal structures of these classifications and new areas can be added. Below is a very general classification of the possible uses of video essays in film studies. This classification has been considered based on previous discussions. The purpose of this classification is not to achieve a sharp and final result, but to look at the existing diversity from a broad perspective.

i. Explanatory video-essays: We can say that explanatory video essays can be about many topics from the narrative features of a film to cinematography techniques. In most of the online viewing platforms, movies are taken under the scrutiny in this way. The most beneficial aspect of this is that the film can be evaluated by a narrator, in the context the narrator has chosen, through explanatory statements and corresponding sections. We can say that one of the areas where such videos can be effective is cinema and TV formation. Illustrative effects, graphics and animations can be used with explanatory sound and montage in such video essays. For example, if we think in the context of filmmaking techniques, one of the most beneficial aspects of it is undoubtedly the ability to reveal and show the formal features that are usually camouflaged behind the emotional impact of a film on the audience during the course. The most distinctive feature of such essays is that they are illustrative. In other words, 
the video itself is a form of expression that supports the subject to be told. These studies can constitute important resources especially for cinema formation.

ii. Video-critique: This is more of a visualization of film criticism. Comments on a film can be presented in voice-over or subtitle format. Sections from the film are brought together to support verbal explanations. Video-critiques can evaluate films mutually, or they can create a comprehensive critique, for example by scrutinizing the entire filmography of a director. Film's narrative, cinematographic, etc. and can present original ideas on these issues. Examples of this form are quite common in video-essays.

iii. Video essays for academic work: It can be said that this is the area that needs to be discussed the most. Video-essays in this field should be considered in a wide range from supporting the existing research methods and reinforcing the expressive effect by illustrating any academic discussion with video, to new performative works and transimagery ways of thinking. Based on the concept of transimagery, new images can be created by establishing connections between images, different studies can be made in the academic field and the diversity in this field can be enriched. It seems that this area needs more discussion since we are talking about an alternative method.

iv. Poetic video-essays: We can define the work that can be produced in this field as a transimagery form of thinking, that is, the production of a new image by the manipulation and bringing together of existing images. What distinguishes this form from the others is that it is a way of thinking that can be created only through images without the need for any textual explanation. We can define this as a form of expression that is somewhat close to video-art. The most interesting aspect of poetic video-essays in this context is that they are a form of expression that allows new experimental ways to express something.

\section{Conclusion}

The fact that video-essays do not yet have a complete form is due to the flexible and variable nature of the video as its raw material. However, this variability can also be considered as an opportunity for diversity and creativity in an academic context. The possibilities of video enable a transimagery way of thinking that reveals a relationship between images and creates new images from this relationship. This way of thinking can form the basis of a performative method in film studies. The possibilities of video should be used more widely in the field of film studies and the nature of these possibilities should be discussed. In this way, it is possible to discuss the moving image that we are thinking about by using its own medium. Today's technological devices allow this to be done easily. However, this requires a more in-depth discussion of some of the above categories. Perhaps three basic steps that can be taken to discuss and study more about this issue can be summarized as follows.

1. Undergraduate, graduate and doctorate courses on video-essays can be included in the education process within the scope of cinema and television education programs.

2. In addition, video essays can be included in the online platforms of academic journals.

3. Also, various conferences, meetings and seminars on how to think of video-essays as a research method in the context of a performative research can bring different ideas together on this topic. 


\section{References}

Baker, Ulus, (2015). Beyin Ekran (çev. T. Bora, K. Ünüvar). Birikim Yayınları, İstanbul

Deleuze, Gilles, (2013). Müzakereler, (çev. İ. Uysal). Norgunk Yayınları, İstanbul.

Dougless, Kitrina ve Carless, David, (2013). "An Invitation to Performative Research". Methodological Innovations Online, 8(1), 53-64.

Eisner, Elliot, (2008). Art and Knowledge. (ed. J. G. Knowles ve A. L. Cole). Handbook of The Arts in Qualitative Research (s. 3-12). Sage Poblications, California

Frampton, Daniel, (2013). Filmozofi. (çev. C. Soydemir). Metis Yayınları, İstanbul

Grant, Catherine, (2016). The Audiovisual Essay as Performative Research. NECSUS European Journal of Media Studies, 5(2), 255-265. doi:10.25969/mediarep/3370.

Gürkan, İpek (2019). “Film Çalışmalarında Eleştirinin Dönüşümü: Görsel-İşitsel Denemeler (Audiovisual Essay). Sinefilozofi, 4(8), 284-303. doi:10.31122/sinefilozofi.633100

Haseman, Brad, (2006). "A Manifesto for Performative Research". Media International Australia Incorporating Culture and Policy; (118), 98-106.

Havelock, Erik, (2014). Yunan Mirası (ed. D. Crowley ve P. Heyer), İletişim Tarihi (çev. B. Ersöz). Siyasal Yayınevi, Ankara.

Keathley, C. (2011). La Caméra-Stylo: Notes On Video Criticism and Cinephilia. (ed. A. Clayton ve A. Klevan). The Language and Style of Film Criticism (s. 176-192). Routledge, New York.

Langer, Susan, K., (1957). Problems of Art: Ten Philosphical Lectures. Charles Scribner's Sons, New York.

Logan, R. K., (2014). Alfabe Etkisi. (ed. D. Crowley ve Heyer), İletişim Tarihi (B. Ersöz, Çev.). Siyasal Yayınevi, Ankara.

Lopez, C. Alvarez., \& Martin, Adrian, (2015). The Audiovisual Essay As Art Practice. NECSUS European Journal of Media Studies, 81-83. doi:10.5117/NECSUS2015.1.LOPE

McLuhan, Marshall, (2001). Gutenberg Galaksisi: Tipografik İnsanın Oluşumu. (G. G. Çağalı, Çev.), Yapı Kredi Yayınları, İstanbul.

Mcwhirter, Andrew, (2015). Film Criticism, Film Scholarship and The Video Essay. Screen, 3(56), 369-377. doi:10.1093/screen/hjv044

Polanyi, Michael (2009). Tacit Dimension. The University of Chicago Press, Chicago

Rowland, D. W. (2014). Giriş. D. Crowley, \& P. Heyer (Dü) içinde, İletişim Tarihi (B. Ersöz, Çev.). Ankara: Siyasal Yayınevi.

Saldana, Johnny, (2005). An Introduction To Etnodrama. (ed. J. Saldana ve J. Saldana), Ethnodrama: An Anthology of Reality Theater (s. 1-36). Walnut Creek: Altamira Press.

Shambu, Girish, (2020). Yeni Sinefili, (çev. B. Demirtaş), Yort, Eskişehir.

Smith, D. (2011, Haziran 10). Mubi.com. Projectcinephilia: https:/ / projectcinephilia. mubi.com/2011/06/10/eyes-wide-shut-notes-toward-a-new-video-criticism/ adresinden alınd 1 